\title{
PERBAIKAN PROSES PRODUKSI DENGAN STANDAR CARA PRODUKSI PANGAN YANG BAIK (CPPB) DAN WORK IMPROVEMENT IN SMALL ENTERPRISE (WISE) PADA INDUSTRI KERUPUK SALA
}

\author{
Bambang Suhardi \\ Fakultas Teknik, Program Studi Teknik Industri \\ Universitas Sebelas Maret Surakarta \\ Email: bambangsuhardi@staff.uns.a.id \\ Maria Kadita \\ Fakultas Teknik, Program Studi Teknik Industri \\ Universitas Sebelas Maret Surakarta \\ Email: mariakadita94@gmail.com \\ Pringgo Widyo Laksono \\ Fakultas Teknik, Program Studi Teknik Industri \\ Universitas Sebelas Maret Surakarta \\ Email: pringgo@ft.uns.ac.id
}

\begin{abstract}
ABSTRAK
Kerupuk merupakan makanan kering khas Indonesia yang terbuat dari bahan dasar tepung tapioka dan sudah sangat dikenal oleh masyarakat. Industri kerupuk yang banyak tersebar di wilayah Indonesia sebagian besar masih merupakan Industri Rumah Tangga (IRT) yang proses produksinya dikerjakan secara tradisional. Setiap industri rumah tangga yang menghasilkan olahan pangan wajib memiliki SPP-IRT (Sertifikat Produksi Pangan Industri Rumah Tangga). SPP-IRT diperlukan oleh pelaku IRT agar dapat memperluas pasar penjualan dan memasuki pasar ritel modern. Untuk mendapatkan SPP-IRT terdapat beberapa aspek yang dinilai sesuai dengan peraturan CPPB (Cara Produksi Pangan yang Baik) yang diatur oleh BPOM. Penelitian ini bertujuan untuk mengevaluasi penerapan CPPB pada IRT kerupuk SALA dengan menggunakan daftar periksa CPPB-WISE sebagai upaya perbaikan proses produksi dan pemenuhan standar untuk mendapatkan SPP-IRT. Penelitian ini terdiri dari tujuh tahap yaitu identifikasi kondisi di kerupuk SALA, pemeriksaan daftar periksa CPPB di industri kerupuk SALA, pemeriksaan daftar periksa WISE di industri kerupuk SALA, penyusunan daftar periksa CPPB-WISE, pembobotan kriteria dan subkriteria daftar periksa CPPB-WISE dengan metode AHP, rekapitulasi pembobotan daftar periksa CPPB -WISE, dan usulan alternatif perbaikan proses produksi. Berdasarkan hasil penelitian dapat disimpulkan bahwa terdapat lima kriteria yang menjadi prioritas perbaikan berdasarkan evaluasi penilaian daftar periksa GMP-WISE dan juga diberikan usulan berupa penerapan budaya kerja 5S (Seiri, Seiton, Seiso, Seiketsu, dan Shitsuke) di IRT kerupuk SALA
\end{abstract}

Kata kunci: kerupuk, cara produksi pangan yang baik, work improvement in small enterprise, SPP-IRT, $5 \mathrm{~S}$.

\section{ABSTRACT}

Kerupuk is a typical Indonesian dry food made from tapioca flour and is well known by the people. Kerupuk industries that widely spread in the territory of Indonesia, majority are still a Household Industry or Industri Rumah Tangga (IRT) which the production process is done traditionally. Every home industry that produces processed food is required to have SPP-IRT (Sertifikat Produksi Pangan Industri Rumah Tangga or Food Production Certificate of Household Industry). SPP-IRT is required by IRT's actors in order to expand the sales market and enter the modern retail market. In order to obtain SPP-IRT there are several aspects that are assessed in accordance with CPPB (Cara Produksi Pangan yang Baik or Good Manufacturing Practices) rules regulated by BPOM. This study aims to evaluate the application of CPPB on IRT of Kerupuk SALA using CPPB-WISE checklist as an effort to improve production process and standard fulfillment to get SPP-IRT. This research consists of seven stages which are identification of conditions in kerupuk SALA, checking CPPB checklist in SALA kerupuk industry, checking WISE checklist in SALA kerupuk industry, preparation of CPPB-WISE checklist, weighting criteria and sub-criteria of CPPB-WISE checklist with AHP method, recapitulation of the weighting of CPPB-WISE checklist, and alternative proposal for improvement of production process. Based on the research results, it can be 
concluded that there are five criteria that become priority improvement based on evaluation of GMP-WISE checklist and also proposed in the form of 5 S (Seiri, Seiton, Seiso, Seiketsu, and Shitsuke) working culture in IRT of SALA Kerupuk.

Keywords: crackers, good manufacturing practices, work improvement in small enterprise, SPP-IRT, $5 S$

\section{PENDAHULUAN}

Kerupuk merupakan makanan kering khas Indonesia yang terbuat dari bahan dasar tepung tapioka dan sudah sangat dikenal oleh masyarakat. Konsumsi kerupuk biasanya bukan sebagai makanan utama melainkan sebagai makanan kecil, makanan ringan atau sebagai pelengkap hidangan. Industri kerupuk banyak tersebar di wilayah Indonesia, dan sebagian besar masih merupakan Industri Rumah Tangga (IRT) atau Usaha Kecil dan Menengah (UKM) yang proses produksinya dikerjakan secara tradisional.

Mengacu pada Pasal 43 Peraturan Pemerintah Nomor 28 Tahun 2004 Tentang Keamanan, Mutu, dan Gizi Pangan mengamanatkan bahwa pangan olahan yang diproduksi oleh industri rumah tangga wajib memiliki Sertifikat Produksi Pangan Industri Rumah Tangga (SPP-IRT) yang diterbitkan oleh Bupati/Walikota dan Kepala Badan Pengawasan Obat dan Makanan (BPOM) menetapkan pedoman pemberian SPP-IRT [2]. SPP-IRT diperlukan oleh pelaku IRT agar dapat memperluas pasar penjualan produknya. Selain itu, SPP-IRT digunakan sebagai salah satu syarat produk IRT dapat memasuki jaringan pasar ritel modern. Untuk mendapatkan SPP-IRT terdapat beberapa aspek yang dinilai sesuai dengan peraturan Cara Produksi Pangan yang Baik untuk industri rumah tangga (CPPB-IRT) yang diatur oleh BPOM.

Salah satu industri kerupuk yang sudah lama berdiri adalah IRT kerupuk SALA yang berada di Kabupaten Boyolali. Perusahaan sedang berusaha menambah jumlah produksi kerupuk dan memperluas pasar distribusi di luar Kabupaten Boyolali. Faktor penghambat adalah belum adanya SPP-IRT yang dimiliki perusahaan. Berdasarkan permasalahan tersebut, maka perlu dilakukan evaluasi penerapan CPPB pada kerupuk SALA Boyolali sebagai upaya perbaikan proses produksi dan pemenuhan standar untuk mendapatkan SPP-IRT. Hasil pengamatan menunjukkan bahwa dalam proses produksi kerupuk masih banyak aspek yang belum sesuai dengan standar CPPB yang berlaku. Hal ini dapat dilihat dari faktor kebersihan ruang produksi yang terlihat kotor dan gelap, lantai produksi yang berwarna hitam, serta pada atap ruang produksi terdapat sarang serangga dan juga debu yang berpotensi menyebabkan kontaminasi bahan pangan dengan sumber pencemar. Selain itu kebersihan pencucian peralatan yang kontak langsung dengan bahan pangan belum begitu diperhatikan. Faktor lain seperti higiene yang berkaitan dengan kebersihan dan kebiasaan karyawan, seperti tidak adanya baju produksi untuk pekerja yang kontak langsung dengan pangan, dan kebiasaan pekerja yang minum dan merokok di ruang produksi.

Untuk mendukung industri kerupuk SALA melakukan perbaikan proses produksi, maka perbaikan proses produksi tersebut didasarkan pada standar CPPB serta metode WISE (Work Improvement in Small Enterprise) yang dikeluarkan oleh International Labour Organization (ILO) untuk memberikan perbaikan dari segi kondisi kerja [3]. Kedua aspek tersebut yaitu CPPB dan WISE diaplikasikan untuk mendapatkan rekomendasi perbaikan proses produksi kerupuk SALA agar mendapatkan peningkatan produktivitas pada proses produksi serta kondisi kerja yang lebih aman, sehat, dan nyaman. Metode CPPB (Good Manufacturing Practices) telah banyak digunakan untuk menilai keamanan pangan di industri makanan dan minuman [1], [5], [6], [7], [8], [11]. Metode WISE untuk menilai pelaksanaan kesehatan dan keselamatan kerja di industri kecil dan menengah [4].

\section{METODOLOGI PENELITIAN}

Penelitian ini diawali dengan melakukan studi lapangan dan studi literatur untuk melakukan identifikasi permasalahan yang terjadi di IRT Kerupuk Sala. Berdasarkan identifikasi masalah yang telah dilakukan tersebut kemudian digunakan untuk menyusun rumusan masalah dan tujuan masalah. Tahap selanjutnya yaitu tahap pengumpulan dan pengolahan data.

\subsection{Tahap Evaluasi Kondisi Saat Ini Dengan CPPB Dan WISE}

Pada tahap ini dilakukan evaluasi kondisi saat ini di IRT berdasarkan pada kriteria dalam pedoman Cara Produksi Pangan yang Baik (CPPB) yang telah dikeluarkan BPOM dan Work Improvement in Small Enterprise (WISE) milik ILO. Evaluasi dilakukan dengan memberikan penilaian pada kriteria tersebut. Suatu kondisi dikatakan prioritas apabila kondisi di IRT saat ini membutuhkan perbaikan dan tidak sesuai dengan standar Cara Produksi Pangan yang Baik (CPPB) dan Work Improvement in Small Enterprise (WISE). Sedangkan kondisi dikatakan tidak prioritas apabila kondisi di IRT tidak membutuhkan perbaikan 
dan sesuai dengan pedoman Cara Produksi Pangan yang Baik (CPPB) dan Work Improvement in Small Enterprise (WISE).

\subsection{Tahap Penyusunan Daftar Periksa CPPB-WISE}

Penyusunan daftar periksa CPPB-WISE didapatkan dari hasil evaluasi kondisi saat ini dengan kriteria dan subkriteria pada pedoman CPPB dan WISE yang menjadi prioritas perbaikan. Sedangkan kriteria dan subkriteria yang tidak prioritas tersebut akan dieliminasi dan tidak digunakan dalam penyusunan daftar periksa CPPB-WISE. Selain itu, penentuan kriteria dan subkriteria juga didasarkan pada tinjauan pustaka dari penelitian mengenai penilaian proses produksi UKM tempe menggunakan Good Manufacturing Practice (GMP) dan Work Improvement in Small Enterprice (WISE) [8].

\subsection{Tahap Pembobotan Kriteria Penilaian}

Penilaian kondisi kerja IRT dari daftar periksa CPPB-WISE kemudian diolah dengan bantuan kuesioner Analytical Hierarchy Process (AHP) oleh beberapa responden yang ahli dibidangnya [9]. Berdasarkan hasil kuesioner AHP dan pengolahan dari daftar periksa ini nantinya akan diperoleh urutan kriteria yang harus diperbaiki terlebih dahulu.

\subsection{Tahap Usulan Perbaikan}

Pada tahap ini dilakukan perancangan usulan perbaikan yang akan dilakukan di IRT Kerupuk SALA. Perbaikan proses produksi dilakukan berdasarkan hasil pembobotan kriteria pada daftar periksa CPPBWISE.

\section{HASIL DAN PEMBAHASAN}

Hasil yang diperoleh dari penelitian menunjukkan beberapa hasil penilaian dan análisis yang meliputi pemeriksaan daftar periksa CPPB-WISE, penyusunan daftar periksa CPPB-WISE, pembobotan kriteria daftar periksa CPPB-WISE, dan usulan perbaikan proses produksi di IRT Kerupuk SALA.

\subsection{Pemeriksaan Daftar Periksa CPPB-WISE}

Pemeriksaan daftar periksa CPPB-WISE di IRT Kerupuk SALA dilakukan berdasarkan kriteria dalam standar Cara Produksi Pangan yang Baik (CPPB) dan Work Improvement in Small Enterprise (WISE). Terdapat 14 kriteria dalam pedoman CPPB dan 8 kriteria dalam pedoman WISE. Pemeriksaan dilakukan untuk mengetahui kesesuaian kondisi saat ini di IRT dengan pedoman yang berlaku.

Pemeriksaan daftar periksa CPPB-WISE dilakukan pada semua kriteria dalam pedoman CPPB dan WISE. Pemeriksaan tersebut dilakukan dengan menilai kriteria yang dinilai menjadi prioritas dan tidak prioritas dalam perbaikan proses produksi. Berdasarkan hasil pemeriksaan diperoleh hasil bahwa pada standar CPPB terdapat 10 kriteria yang masuk dalam kategori prioritas dan 4 kriteria yang masuk dalam kategori tidak prioritas. Sedangkan pada pedoman WISE terdapat 5 kriteria yang masuk dalam kategori prioritas dan 3 kriteria yang masuk dalam kategori tidak prioritas.

\subsection{Penyusunan Daftar Periksa CPPB-WISE}

Penyusunan daftar periksa CPPB-WISE ini digunakan untuk menentukan prioritas perbaikan proses produksi yang akan dilakukan di IRT Kerupuk SALA. Daftar periksa CPPB-WISE ini terdiri dari 5 kriteria dan 21 sub kriteria dan ditunjukkan pada Tabel 1. 
Tabel 1. Daftar Periksa CPPB-WISE

\begin{tabular}{|c|c|c|}
\hline No & Kriteria & Sub Kriteria \\
\hline \multirow{5}{*}{1} & \multirow{4}{*}{ Pengendalian proses produksi } & Penetapan komposisi bahan \\
\hline & & Penetapan cara produksi baku \\
\hline & & Pencatatan dan dokumentasi \\
\hline & & Penanggulangan bahaya kebakaran \\
\hline & & Keadaan sekitar lingkungan \\
\hline \multirow[t]{4}{*}{2} & \multirow[t]{4}{*}{ Desain tempat kerja } & Kondisi bangunan dan kelengkapannya \\
\hline & & Lingkungan kerja \\
\hline & & Kebersihan penanganan material \\
\hline & & Penyimpanan bahan non pangan \\
\hline \multirow[t]{5}{*}{3} & \multirow{5}{*}{$\begin{array}{l}\text { Penyimpanan dan penanganan } \\
\text { material dan peralatan }\end{array}$} & Pemeriksaan peralatan produksi \\
\hline & & Kebersihan peralatan produksi \\
\hline & & Pengawasan penyimpanan material \\
\hline & & Peralatan penanganan material \\
\hline & & Pengadaan fasilitas higiene \\
\hline \multirow[t]{4}{*}{4} & \multirow[t]{4}{*}{ Program higiene dan sanitasi } & Higiene karyawan \\
\hline & & Pengawasan program higiene dan sanitasi \\
\hline & & Program pencegahan dan pengendalian hama \\
\hline & & Pelatihan karyawan \\
\hline \multirow[t]{3}{*}{5} & Organisasi pekerjaan & Perlengkapan perlindungan karyawan \\
\hline & & Program perlindungan karyawan \\
\hline & & Kebiasaan karyawan \\
\hline
\end{tabular}

Kriteria dan subkriteria diperoleh dari hasil pemeriksaan daftar periksa CPPB-WISE yang dinilai menjadi prioritas perbaikan. Kriteria dan subkriteria yang tidak menjadi prioritas akan dieliminasi dan tidak digunakan dalam penyusunan daftar periksa CPPB-WISE.

\subsection{Pembobotan Daftar Periksa CPPB-WISE}

Langkah selanjutnya melakukan pembobotan daftar periksa CPPB-WISE menggunakan metode AHP. Pembobotan ini dilakukan untuk menentukan prioritas perbaikan proses produksi yang akan dilakukan di IRT Kerupuk SALA. Dalam menentukan kriteria mana yang menjadi prioritas perbaikan, skor penilaian tidak serta merta dapat digunakan untuk pengambilan keputusan, karena harus dipastikan apakah kriteria tersebut memiliki bobot atau pengaruh kontribusi untuk IRT.

Tahap awal yang akan dilakukan yaitu melakukan penyusunan struktur hierarki. Tujuan dilakukannya tahap ini adalah untuk menyederhanakan permasalahan yang ada. Struktur hierarki penentuan kriteria dan subkriteria ditunjukkan pada Gambar 1. 


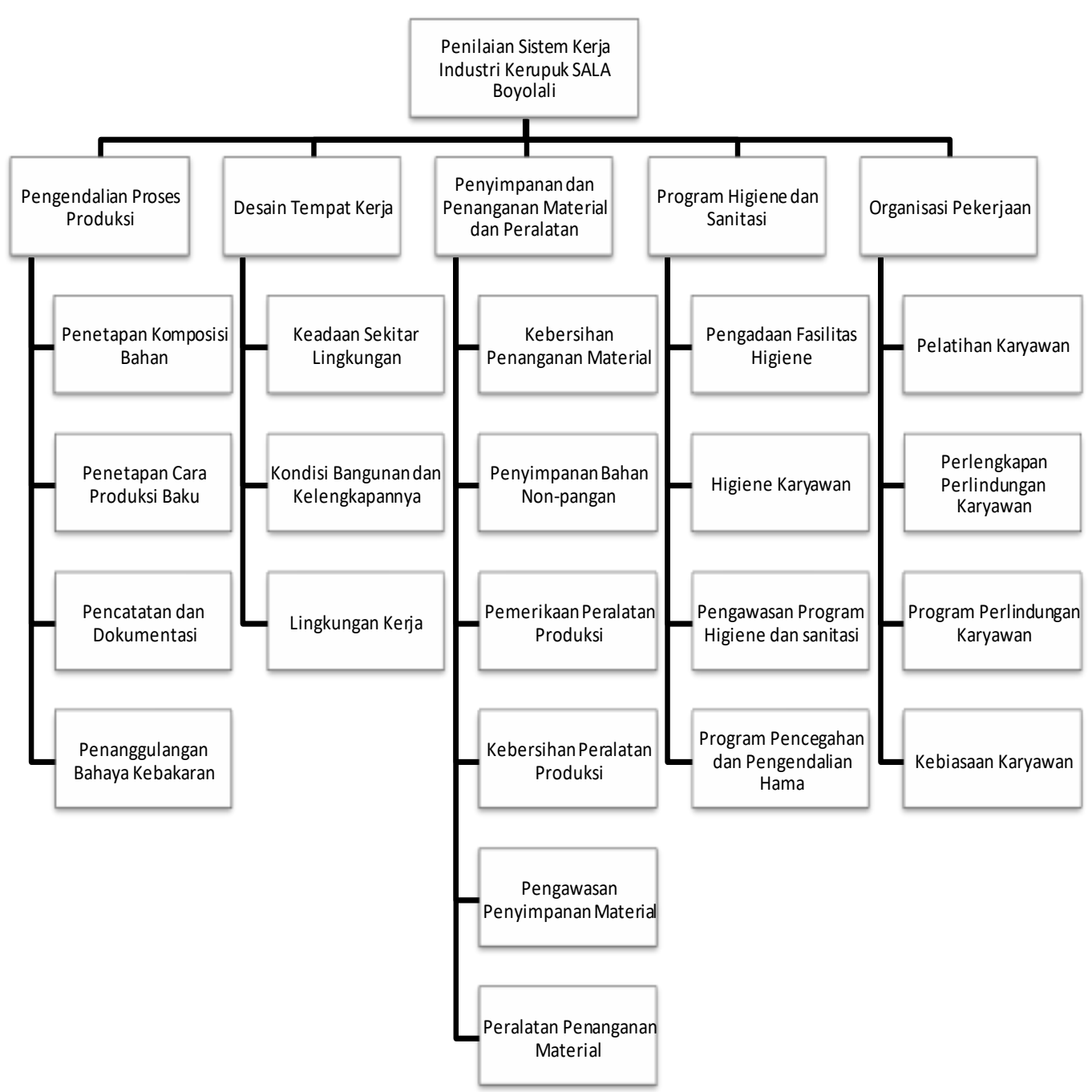

Gambar 1. Struktur Hierarki Penentuan Kriteria Dan Subkriteria Di IRT Kerupuk SALA Boyolali

Setelah dilakukan tahap penentuan kriteria dan subkriteria terpilih, maka dilakukan penyusunan kuesioner. Tujuan penyusunan kuesioner adalah untuk menentukan besarnya bobot penilaian untuk masingmasing kriteria dan subkriteria penilaian proses produksi di IRT Kerupuk SALA.

Hasil penilaian dari kuesioner tersebut diolah dengan metode AHP [9] berdasarkan perbandingan berpasangan menggunakan skala linguistik (1 hingga 9) untuk menentukan kriteria yang paling prioritas untuk dilakukan perbaikan. Metode ini mensintesis perbandingan berpasangan pada setiap level.

Setelah dilakukan penilaian oleh pihak-pihak yang ahli dibidangnya, tahap selanjutnya yaitu perhitungan hasil pembobotan. Perhitungan menggunakan metode AHP ini melalui beberapa tahapan yaitu rekapitulasi hasil penilaian kuesioner, agregasi hasil penilaian responden kuesioner, menghitung vektor prioritas, menghitung bobot prioritas, dan menghitung Consistenty Ratio (CR).

Kemudian dilakukan rekapitulasi pembobotan kriteria dan subkriteria penilaian pada daftar periksa CPPB-WISE. Bobot prioritas kriteria dan subkriteria penilaian proses produksi di IRT Kerupuk SALA Boyolali ditunjukkan pada Tabel 2. 
Tabel 2. Rekapitulasi bobot prioritas kriteria dan subkriteria penilaian proses produksi

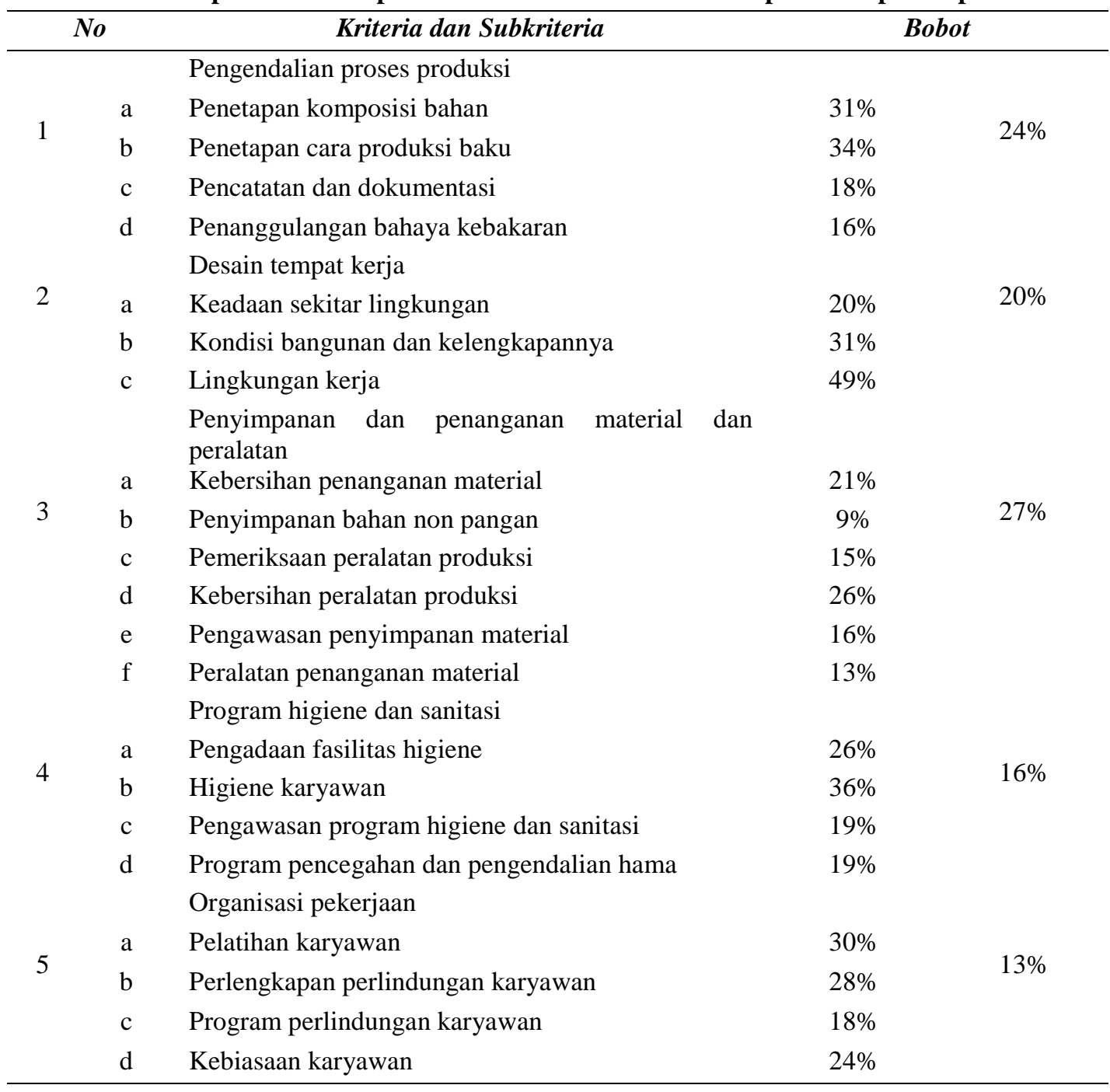

Proses perbaikan akan dilakukan secara bertahap. Proses perbaikan dilakukan pada kriteria yang mempunyai prosentase terbesar berdasarkan kriteria yang terdapat dalam daftar periksa CPPB-WISE. Prosentase prioritas perbaikan tertinggi terdapat pada kriteria penyimpanan dan penanganan material dan peralatan sebesar $27 \%$. Kriteria organisasi pekerjaan mempunyai prosentase terkecil sebesar $13 \%$. Kriteria penyimpanan dan penanganan material dan peralatan mempunyai 6 subkriteria di dalamnya yang juga dilakukan penilaian prioritas perbaikan. Hasil prosentase dari keenam subkriteria tersebut yaitu kebersihan penanganan material sebesar $21 \%$, penyimpanan bahan non-pangan sebesar $9 \%$, kemudian pemeriksaan peralatan produksi sebesar $15 \%$, subkriteria kebersihan peralatan produksi dengan bobot terbesar yaitu $26 \%$, pengawasan penyimpanan material sebesar $16 \%$, dan peralatan penanganan material sebesar $13 \%$.

\subsection{Usulan Perbaikan Proses Produksi Irt Kerupuk Sala Boyolali}

Berdasarkan hasil penilaian proses produksi IRT Kerupuk SALA, maka prioritas perbaikan dilakukan pada kriteria yang memiliki nilai prosentase tertinggi yaitu penyimpanan dan penanganan material dan peralatan. Kriteria penyimpanan dan penanganan material dan peralatan memiliki 6 subkriteria untuk perbaikannya yaitu kebersihan penanganan material, penyimpanan bahan non-pangan, kemudian pemeriksaan peralatan produksi, kebersihan peralatan produksi, pengawasan penyimpanan material, dan peralatan penanganan material.

Penjelasan terhadap subkriteria ini digunakan sebagai dasar dalam melakukan proses perbaikan pada IRT krupuk Sala. Berikut ini merupakan contoh permasalahan yang menjadi prioritas perbaikan proses produksi. 


\subsubsection{Pengawasan Penyimpanan Material}

a. Peraturan yang berlaku adalah tempat penyimpanan material atau produk mudah dibersihkan, bebas dari hama, penerangan cukup dan ada sirkulasi udara [2]. Ruang penyimpanan material dan produk akhir disimpan dalam ruangan tertutup tanpa penerangan dan tidak memiliki rak atau lemari. Dan sirkulasi udara hanya melalui pintu sehingga pengap dan lembab.

b. Bahan pangan tidak boleh tercecer karena mengundang hama [2]. Dalam ruang produksi ditemukan banyak sekali ceceran tepung yang tidak dibersihkan dan juga lama kelamaan mengendap dan lengket di lantai menyebabkan lantai kotor.

c. Penyimpanan bahan baku tidak boleh menyentuh dinding, lantai, atau langit-langit dan ada tempat penyimpanan khusus. [2] \& [3]. Penempatan bahan baku diletakkan di dalam ruang produksi bersebelahan dengan bahan bakar kayu dan tidak dilengkapi rak atau lemari.

Keseluruhan usulan perbaikan yang dilakukan berdasarkan permasalahan yang terjadi saat ini di bagian produksi IRT Kerupuk SALA yaitu dengan penerapan budaya kerja 5S (Seiri, Seiton, Seiso, Seiketsu, Shitsuke). Penerapan budaya kerja 5S dilakukan dengan mengacu pada [10]. Beberapa contoh penerapan 5S di industri krupuk SALA seperti ditunjukkan pada Gambar 2, Gambar 3, Gambar 4 dan Gambar 5.

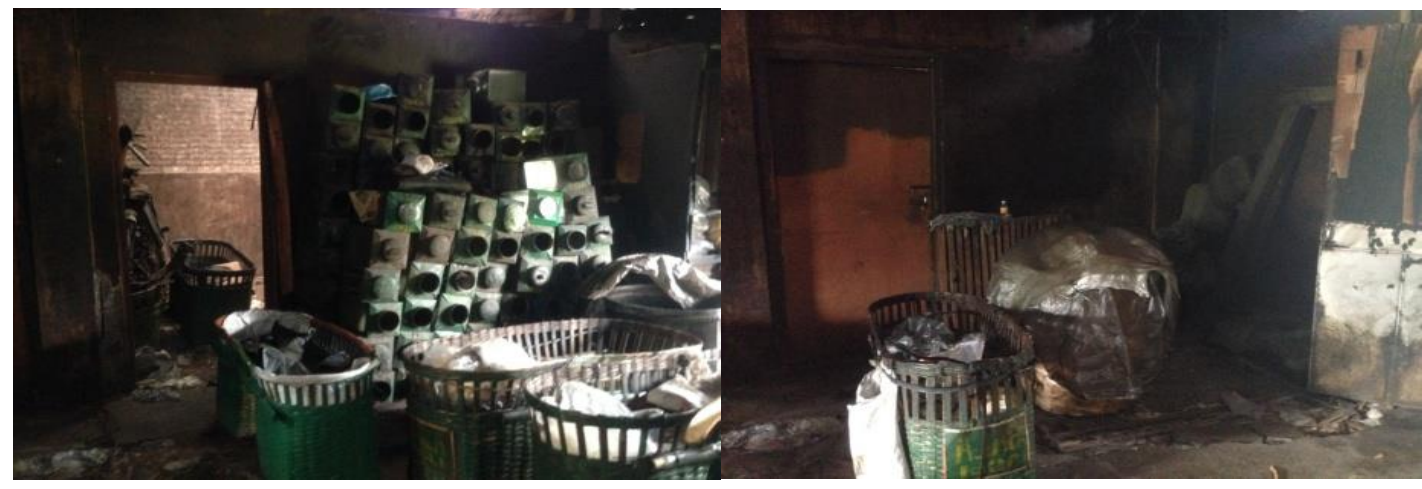

Gambar 2. Sebelum Penerapan Seiri pada Wadah Kerupuk

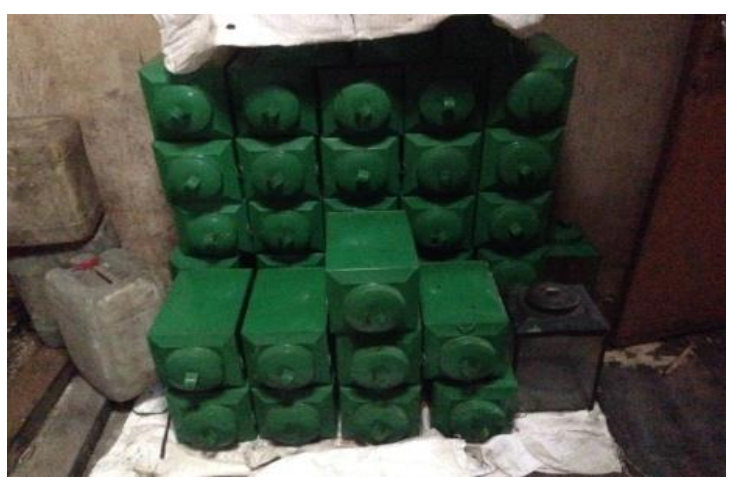

Gambar 3. Setelah Penerapan Seiri Pada Wadah Kerupuk

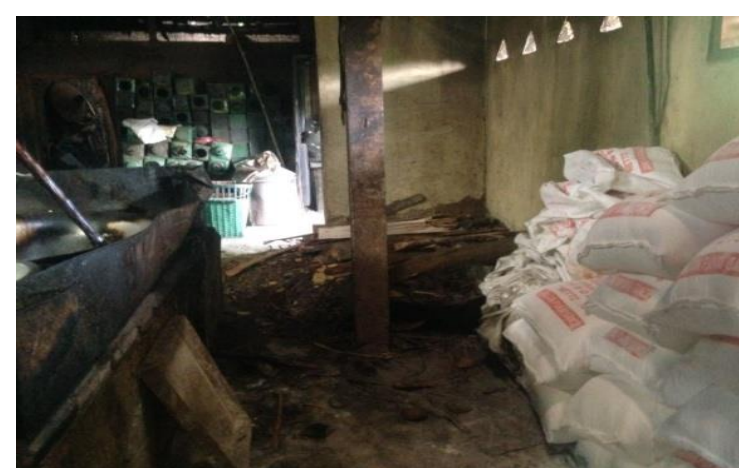

Gambar 4. Sebelum Penerapan Seiton Pada Area Penyimpanan Bahan Baku Dan Kayu Bakar 


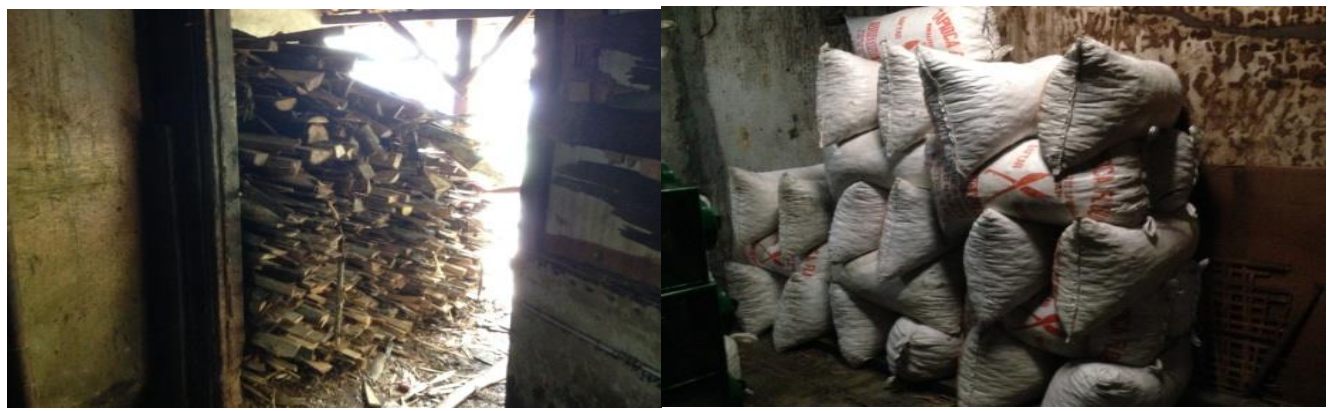

Gambar 5. Setelah Penerapan Seiton Pada Area Penyimpanan Bahan Baku Dan Kayu Bakar

\section{KESIMPULAN}

Kesesuaian kondisi IRT Kerupuk SALA Boyolali dengan standar Cara Produksi Pangan yang Baik (CPPB) adalah sebesar 60,8\% dan kesesuaian dengan standar Work Improvement in Small Enterprise (WISE) adalah sebesar 70\%. Berdasarkan evaluasi penilaian daftar periksa CPPB-WISE terdapat lima kriteria yang menjadi prioritas perbaikan yaitu pengendalian proses produksi, desain tempat kerja, penyimpanan dan penanganan material dan peralatan, program higiene dan sanitasi, dan organisasi pekerjaan. Kriteria utama yang menjadi prioritas perbaikan proses produksi di IRT Kerupuk SALA Boyolali adalah penyimpanan dan penanganan material dan peralatan yang memiliki bobot penilaian terbesar dibandingkan dengan keempat kriteria lainnya yaitu sebesar $27 \%$.

Usulan yang diberikan untuk perbaikan proses produksi di IRT Kerupuk SALA Boyolali yaitu berupa penerapan budaya kerja 5S (Seiri, Seiton, Seiso, Seiketsu, dan Shitsuke). Penerapan Seiri dan Seiton dilakukan pada subkriteria pengawasan dan penyimpanan material, sedangkan penerapan Seiso dilakukan pada subkriteria kebersihan peralatan produksi dan kebersihan penanganan material. Penerapan Seiketsu dan Shitsuke dilakukan sebagai disiplin kerja dari penerapan 3S sebelumnya.

\section{DAFTAR PUSTAKA}

[1] Anggraini, T., dan Yudhastuti, R. 2014. "Penerapan Good Manufacturing Practices pada Industri Rumah Tangga Kerupuk Teripang di Sukolilo Surabaya”. Jurnal Kesehatan Lingkungan Vol. 7, No. 2, 148-158.

[2] BPOM. 2012. Pedoman Cara Produksi Pangan yang Baik untuk Industri Rumah Tangga. Jakarta : Badan Pengawas Obat dan Makanan.

[3] ILO. 2015. Daftar Periksa Pembinaan Peningkatan Keselamatan dan Kesehatan Kerja pada Usaha Kecil dan Menengah dengan Metode Pelatihan Prtisipasi Aktif. Jakarta : Kementrian Ketenagakerjaan Republik Indonesia.

[4] Islami, S. B. 2013. Analisis Penilaian Penerapan Kesehatan dan Keselamatan Kerja pada Industri Kecil dan Menengah dengan Menggunakan Metode WISE. Skripsi. Surabaya : Institut Teknologi Sepuluh November.

[5] Lisyanti., Palupi, N.S., Kadarisman, D., 2009. "Evaluasi Penerapan Cara Produksi yang Baik (Good Manufacturing Practices) dan Penyusunan SSOP Industri Lidah Buaya di PT. Libe Bumi Abadi”. Jurnal MPI, Vol 4, No. 1, 90-109

[6] Purba, D.F., Nuraida, L., Koswara, S., 2014. "Efektivitas Program Peningkatan Mutu dan Keamanan Pangan Industri Rumah Tangga Pangan (IRTP) di Kabupaten Cianjur”. Jurnal Standardisasi Vol 16, No.2 .103-112

[7] Putri, Rr. Asri, I., Rohayati, Y., Aisha, A.N., 2015. "Evaluasi Pemenuhan Kriteria CPPB-IRT dan Sertifikasi Halal Pada UKM Pelangi Rasa”. Jurnal Rekayasa Sistem \& Industri Vol. 2, No. 3, 17-24

[8] Rachmi, D., 2013. Penerapan Good Manufacturing Practice dan Work Improvement In Small Enterprise pada Usaha Kecil dan Menengah untuk Pemenuhan Standar Kesehatan (Studi Kasus : UKM Tempe Tenggilis Mejoyo Surabaya). Skripsi. Surabaya : Institut Tekonologi Sepuluh November.

[9] Saaty, T. L., 2008. "Decision Making with The Analytic Hierarchy Process". International Journal, Vol. 1, No. 1, 83-98.

[10] Suwondo, C., 2012. "Penerapan Budaya Kerja Unggulan 5S (Seiri, Seiton, Seiso, Seiketsu, dan Shitsuke) di Indonesia”. Jurnal Magister Manajemen, Vol. 1, No.1.

[11] Yusra., 2016. "Kajian Penerapan GMP dan SSOP pada Pengolahan Ikan Nila (Oreochronis niloticus) Asap di Kecamatan Tanjung Raya Kabupaten Agam”. Jurnal Katalisator Vol. 1 No. 1, 10-19. 